

\section{COMPUTER SOFTWARE CONFIGURATION MANAGEMENT PLAN FOR THE HONEYWELL MODULAR AUTOMATION SYSTEM}

\section{L.T. Cunningham}

B \& W Hanford Co. . Richland. WA 99352

U.S. Department of Energy Contract DE-AC06-87RL10930

$\begin{array}{llll}\text { EDT/ECN: } & 619160 & \text { UC: UC-506 } & \\ \text { Org Code: } & 15530 & \text { Charge Code: } & \text { K6134 } \\ \text { B\&R Code: } & \text { EW7003000 } & \text { Total Pages: } 15\end{array}$

Key Words: Honeywe11, Modular Automation System. Computer Software Management Plan

Abstract: This document provides a Computer Software management plan for a new Honeywel1 Modular Automation System (MAS) being installed in the Plutonium Finishing Plant (PFP). This type of system will be used to control new thermal stabilization furnaces, a vertical denitrator calciner, and a pyrolysis furnace.

Honeywell is registered trademark of Honeywell Inc. Minneapolis. MN. Intellution and FIX DMACS are registered trademarks of Intellution, Inc. INTEL and Pentium are registered trademarks of INTEL Corp.

Microsoft Windows and Excel are registered trademarks of Microsoft Corp.

TRADEMARK DISCLAIMER. Reference herein to any specific commercial product. process, or service by trade name, trademark, manufacturer, or otherwise, does not necessari7y constitute or imply its endorsement. recommendation. or favoring by the United States Government or any agency thereof or its contractors or subcontractors.

Printed in the United States of America. To obtain copies of this document, contact: WHC/BCS Document Control Services, P.0. Box 1970. Mailstop H6-08, Richland WA 99352 (509) 372-2420; Fax (509) 376-4989.
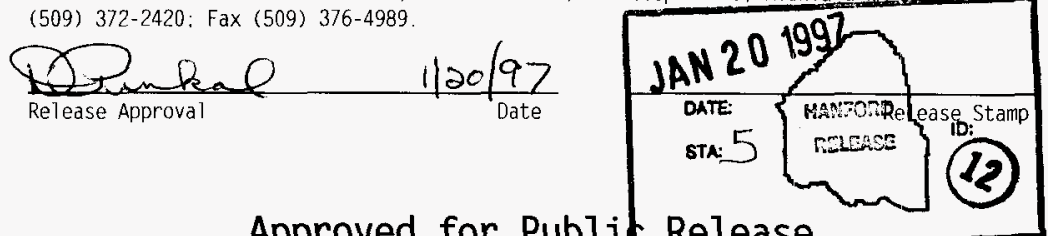

Approved for Publit Release 
TABLE OF CONTENTS

1.0 INTRODUCTION . . . . . . . . . . . . . . . . . . . . . . . . . 3

1.1 PURPOSE . . . . . . . . . . . . . . . . . . . . . . . . . 3

1.2 SCOPE . . . . . . . . . . . . . . . . . 3

1.3 DEFINITIONS . . . . . . . . . . . . . . . . . . . . . . . . . . . . . . 4

1.4 SECURITY . . . . . . . . . . . . . . . . . . . . . . . 6

1.5 HARDWARE/SOFTWARE DESCRTPTION .............. . . 6

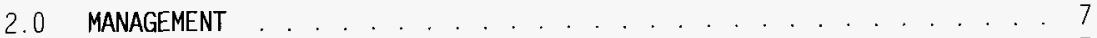

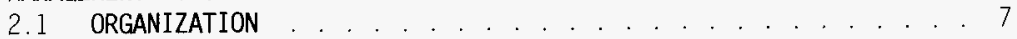

2.1.1 System Administrator . . . . . . . . . . . . . . . . . 8

2.1.2 Engineer . . . . . . . . . . . . . . . . . . . . . . 8

2.1.3 Operator . . . . . . . . . . . . . . . . . . . . . . . 8

2.2 RESPONSIBILITIES . . . . . . . . . . . . . . . . . . . . . . . . 8

2.2.1 Cognizant Manager . . . . . . . . . . . . . . . . . . . . 8

2.2.2 System Cognizant Engineer . . . . . . . . . . . . . . . 8

2.2.3 System Administrator . . . . . . . . . . . . . . . . . . . . 9

2.2.4 Configuration Management . . . . . . . . . . . . . . . . 9

2.3 INTERFACE CONTROLS . . . . . . . . . . . . . . . . . . . . . . . . . . . 9

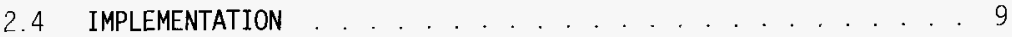

2.5 POLICIES, DIRECTIVES, AND PROCEDURES . . . . . . . . . 10

3.0 ACTIVITIES . . . . . . . . . . . . . . . . . . . . . . . 10

3.1 CONFIGURATION IDENTIFICATION . . . . . . . . . . . . 10

3.1.1 Software Documentation . . . . . . . . . . . . . . 10

3.1 .2 System Software Identification . . . . . . . . . . . . . 10

3.1.2.1 Honeywell Control Software . . . . . . . 10

3.1.2.2 Software Configuration Files . . . . . . . . 10

3.1.2.3 Graphical Files ............ . 11

3.1.3 Problems, Faults and Failures . . . . . . . . . . . 12

3.2 CONFIGURATION CONTROLS . . . . . . . . . . . . . . 12

3.2.1 Software Changes . . . . . . . . . . . . . . . . . . 12

3.2 .2 Access Levels . . . . . . . . . . . . . . . . . . . . . 12

3.2.3 Backup and Recovery Operations . . . . . . . . . . . . . 13

3.2.4 Historical Data File . . . . . . . . . . . . . . . . . . 14

3.3 CONFIGURATION STATUS ACCOUNTING . . . . . . . . . . . . . 14

4.0 TOOLS, TECHNIQUES, AND METHODOLOGIES . . . . . . . . . . . . . 14

5.0 SUPPLIER CONTROL . . . . . . . . . . . . . . . . . . . . . . 14

6.0 RECORD COLLECTION AND RETENTION . . . . . . . . . . . . . . . 14

7.0 REFERENCES . . . . . . . . . . . . . . . . 15 


\subsection{INTRODUCTION}

\subsection{PURPOSE}

The purpose of this document is to establish a Computer Software Configuration Management Plan (CSCMP) for controlling the Plutonium Finishing Plant (PFP) Honeywel 1 Modular Automation System (MAS) with Intellution ${ }^{\circledR}$ FIX DMACS ${ }^{\top M}$ operator interface. Figure 1 shows a system that wi11 be used to control thermal stabilization furnaces in glovebox HA-21I and provide temperature and some interlock control for the vertical denitration calciner (VDC) in $\mathrm{HC}-230-\mathrm{C} 2$. Figure 2 is a system that will be dedicated to control the pyrolysis furnace and of $f$-gas treatment equipment to be installed in $\mathrm{HC}-15$

This CSCMP identifies and defines the configuration items for each system, controls the release and change of these items throughout the system life cycle, records and reports the status of configuration items and change requests, and verifies the completeness and correctness of each item.

\subsection{SCOPE}

The Honeywe 11 MAS and Intellution software installed at PFP will monitor and control thermal stabilization furnaces in glovebox HA-21I and pyrolysis furnaces in $\mathrm{HC}-15$. The system wi 11 monitor and provide temperature control for the VDC in $\mathrm{HC}-230-\mathrm{C} 2$

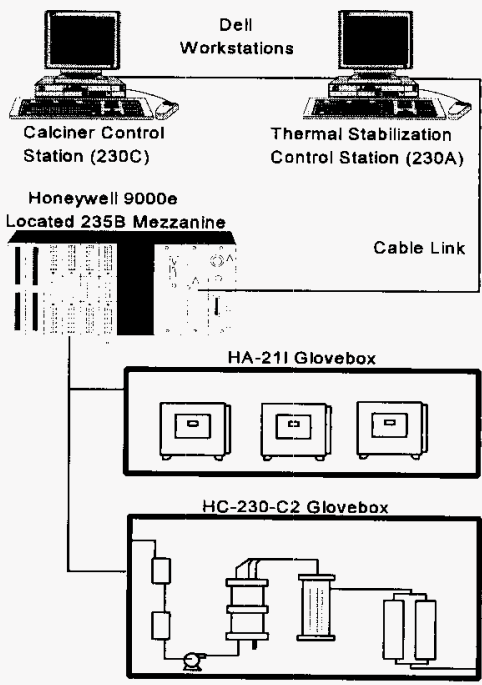

Figure 1

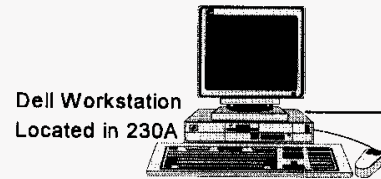

Honeywell 9000e

Located 228B

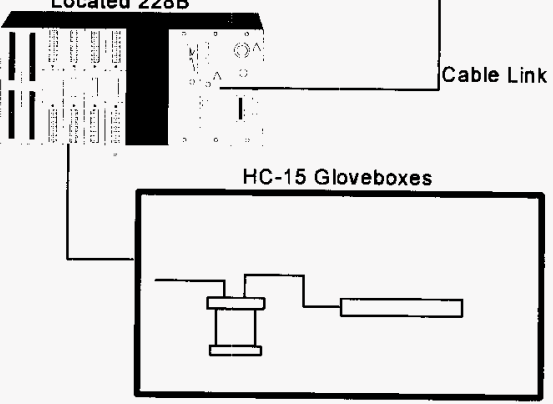

Figure 2 
WHC-SD-CP-CSCM-009, Rev. 0

1.2 SCOPE (cont.)

This plan applies to PFP Process Engineering Cognizant Manager and Stabilization Cognizant Engineers responsible for the Honeywell MAS software/hardware and administration of the Honeywell System. This document also applies to support engineers and operations personnel who have access to the system.

\subsection{DEFINITIONS}

\section{Commercial Software}

Licensed or copyrighted off-the-shelf software that is not subject to Hanford design or specification requirements unique to Hanford and is typically used in applications other than Hanford facilities. This software is typically ordered from the manufacture or supplier because of requirements set forth in the manufacturer's published product description (such as catalogs). Commercial software includes operating systems, language processors, spread sheets, etc.

\section{Computer Software Validation}

The process of evaluating computer software at the end of the computer software development process to ensure compliance with computer software requirements. Validation of the Honeywell MAS will be done with Acceptance Test Procedures (ATP). WHC-SD-CP-ATP-071 was used to validate the software and Input/Output (I/0) for thermal stabilization portion of software and hardware. Additional tests will be done to check VDC and pyrolysis furnace software and I/0. Once equipment installation is complete. Operability Test Procedures (OTP) will be done to confirm the link between software and field equipment.

WHC-SD-CP-OTP-156 was done for thermal stabilization furnaces.

Additional tests will be written and performed for the VDC and pyrolysis furnaces.

\section{Configuration Management}

A discipline applying technical and administrative direction and surveillance to: identify and document function and physical characteristics of a configuration item, control and implementation status, and verify compliance with specified requirements. 


\subsection{DEFINITIONS (cont.)}

\section{PC Supervisor (PCS)}

A single-user operator interface and configuration station for the $\$ 9000$ Controller. Both functions can be active concurrently. so one window can display an operating graphic while another displays a control chart.

\section{$\$ 9000$ Controller}

Honeywel1 controller for continuous and batch applications that integrates sequential, continuous, and fast logic control. The 59000 can have up to 32 PID loops and 1000 inputs/outputs (the recommended limit for flow or pressure control is 16 loops).

\section{Software}

Computer programs, procedures, and possible associated documentation and data concerning operation of a computer system. This includes user-provided instruction and data that implement preprogrammed algorithms in control systems: computer codes and data that will reside in firmware; and where specified by the cognizant manager, user-provided instructions and data used by commercial software such as spreadsheet and database packages.

\section{Software Custodian}

Designated individual or organization that maintains control of computer software, computer software media, and their access. PFP Process Engineering is responsible for maintaining the Honeywell MAS software.

\section{System Administrator}

Designated individual or organization responsible for the configuration and security scheme for the Honeywell MAS.

\section{System Cognizant Engineer}

Responsible engineer that assumes Cognizant Engineer responsibility for the system as defined by Standard WHC-CM-6-1, Standard Engineering Practices. 
WHC-SD-CP-CSCM-009, Rev. 0

\subsection{DEFINITIONS (cont.)}

\section{System Configuration}

Completed data base which allow the control system to set up a specific control and display strategy for each process.

User

The person or persons, who operate or interact directly with the system.

\subsection{SECURITY}

Security for the Honeywell system is provided by limiting access to system through use of passwords. The system administrator controls access through a $\log$ in procedure that consists of a $\log$ in name and a password consisting of up to 20 characters. The access control program is part of the Honeywell PC Supervisor software. This program allows the system administrator to define level of access and breadth of al lowed operations for each user.

\subsection{HARDWARE/SOFTWARE DESCRIPTION}

The Honeywe11 MAS consists of one or more PC work station, a "cable link," and the process control rack.

The work stations are DELL personal computers with INTEL ${ }^{\circledR}$ Pentium ${ }^{\circledR}$ processor and operates in a Microsoft ${ }^{(8)}$ Windows $^{\text {TM }}$ environment. Available software includes the Honeywell PC supervisor. Intellution ${ }^{\oplus}$ FIX DMACS ${ }^{\text {TM }}$. and Microsoft ${ }^{\circledR}$ Windows ${ }^{T M}$ and Exce $^{T M}$.

The PC work stations are connected to each other and the PLC with a "Cable link," a coaxial cable with 50-ohm terminating resistors.

The process control rack for the thermal stabilization furnaces and the VDC contain the following modules: a Model 9000e logic control processor (9010-012), a 15 amp power supply (620-0083), an Ethernet Loop Processor Module (620-0073), two universal analog input modules (621-0020R). two analog output modules (621-0010AR), a discrete input module (621-1160R). and a discrete output module (621-2150R). Two open slots wil1 remain in the control rack for future expansion. 


\subsection{HARDWARE/SOFTWARE DESCRIPTION (cont.)}

The process rack for pyrolysis will contain the following modules: a Model 9000e logic control processor (9010-012), a 15 amp power supply (620-0083). an Ethernet Loop Processor Module (620-0073), universal analog input module (621-0020R), an analog output module (621-0010AR), a digital input module (621-1100R), and a digital output module (621-2100R). Three open slots will remain in the control rack to allow for future expansion.

The universal analog input modules (621-0020R) can each accept 16 inputs. Individual inputs can be setup for the type of analog signal required. Software set up by the system administrator has configured these inputs to 1 to 5 volts (differential pressure transmitters) or Type $K$ thermocouples where appropriate for thermal stabilization furnaces and vertical denitrator calciner.

Each analog output module (621-0010AR) is capable of 4 output signals. These analog output modules have been factory calibrated and will be used to send 4-20mA control signals to Silicon-Controlled Rectifiers (SCR).

The 621-1160R discrete input modules can accept 16 inputs. The 621-1100R discrete input modules accept 8 input signals. These inputs will be used for furnace door limit switches, exhaust fan power indication. $\mathrm{dP}$ switch, pressure switch. flow switch, and level elements. Each 621-2150R discrete output module has 16 outputs and each 621-2100R has 8 outputs. Some outputs will allow relays to energize and permit power to furnaces and calciner heating elements. These relays are an integral part to the interlock schemes for powering the furnaces and calciner. The remaining outputs will be used to start/stop vacuum fans, start/stop pumps. and open/close solenoid valves.

\subsection{MANAGEMENT}

\subsection{ORGANIZATION}

Three groups of system users are available and these groups are provided an appropriate level of access to data files and other programmable files within the Honeywe 11 MAS. Access levels permit certain operations and exclude others. The breadth of these operations may also be limited depending upon the user group. Individual users can also be given additional abilities dependent on their job function. 


\subsubsection{System Administrator}

The system administrator has access to a 11 functions of the Honeywell MAS. Through the security function, the administrator assigns capabilities to the other user groups.

\subsubsection{Engineer}

The engineering level is immediately below that of the system Administrator. The engineer can make changes to the software configuration and operator displays, but cannot access the security file and password information. An ECN wi1l be required against appropriate documentation to implement any configuration changes.

\section{1 .3 Operator}

The operator group consists of the transition operators and shift managers. The access level for this group provides the functions necessary for operation of the equipment.

\subsection{RESPONSIBILITIES}

\subsubsection{Cognizant Manager}

The cognizant manager is responsible for ensuring configuration management controls identified by this document are used: for determining need and extent of software development: for ensuring appropriate approval and review are obtained in accordance wi th the approval designator; and for ensuring that computer software documentation by or transferred to PFP is assigned an approval designator. The cognizant manager will designate the system administrator.

\subsubsection{System Cognizant Engineer}

The cognizant engineer or delegate for the affected process is responsible for approving $\operatorname{ECN}(s)$ to revise software and for identifying functional requirements within each $E C N$. 
WHC-SD-CP-CSCM-009, Rev. O

\subsubsection{System Administrator}

The system administrator is responsible for identifying the functional requirements of the computer software: for establishing approval designation of computer software documentation: for ensuring configuration management requirements are followed: for overseeing and ensuring configuration and security of system: for approving, implementing and tracking ECNs to system documentation: and for revising existing software.

\subsubsection{Configuration Management}

Configuration Management is responsible for assigning a supporting document number to Computer Software Documents and for releasing Computer Software Documents .

\subsubsection{Information Resource Management}

Information Resource Management (IRM) is responsible for providing appropriate vault storage for record copy of software documentation and for providing appropriate records management requirements.

\subsection{INTERFACE CONTROLS}

The facility system and process P\&ID drawings function as the mechanism that controls and defines system interfaces. Overa11, interfaces between the MAS and process equipment are at discrete/analog input/output terminals. All changes to P\&ID drawings, that show the MAS as the control system. sha11 be approved by the Cognizant Engineer responsible for affected system. The cognizant engineer will notify the system administrator to make appropriate modifications to software and configuration documentation.

\subsection{IMPLEMENTATION}

This document in concert with process specific ATPS and OTPS wi 11 be used to bring the Honeywe 11 MAS on line at the PFP. The Honeywe11 MAS wi11 be considered operational when a 11 users have been trained, necessary group text files have been defined, validated, recorded, and required passwords and access levels have been assigned. The cognizant engineer for each process being brought on-line is responsible for complete implementation of this system to the process equipment. 


\subsection{POLICIES, DIRECTIVES, AND PROCEDURES}

Software wi11 be designed and developed in compliance with WHC-CM-4-2 Qua 7ity Assurance Manual, QR 19.0. "Software Quality Assurance' Requirements." Computer software will be design verified according to WHC-CM-6-1. Standard Engineering Practices, EP 4.1, "Design Verification Requirements," and validated following EP 4.2, "Testing Practices." Computer software Documents will be approved and released in accordance with EP 1.6. "Engineering Data Transmittal," EP 1.7. "Engineering Document Approval and Release Requirements, " and revised following EP 2.2. "Engineering Document Change Controls." Al1 training wi11 be conducted under the general auspices of WHC-CM-2-15, "Training Administration Manual."

\subsection{ACTIVITIES}

\subsection{CONFIGURATION IDENTIFICATION}

\subsubsection{Software Documentation}

A11 software associated with the Honeywell MAS will be documented in supporting document WHC-SD-CP-CSWD-018, Honeywell Modular Automated System Computer Software Documentation.

\subsubsection{System Software Identification}

This supporting document identifies items for controlling revisions and installation.

\subsubsection{Honeywe11 Control Software}

The control software consists of the Honeywell PC supervisor and Intellution ${ }^{\circledast}$ FIX DMACS ${ }^{\text {TM }}$ Release 150 (9000-152. PCS/MASNET S/W). Honeywell part number for this 9 disk software package is $64190 \mathrm{~A}$ through 64198A. Backup to these files will be kept by the system administrator on $3 \frac{1}{2}$ " disks.

\subsubsection{Software Configuration Files}

The continuous control chart (CCC) is the configuration software file for the 59000 Controller that creates loop control graphically through the PC Supervisor. Addresses and point names are used to define source and destination of data within the CCC 
3.1.2.2 Software Configuration Files (cont.)

configuration. These addresses identify physical connection points for field wiring to I/0 modules plus internal I/0 and registers for the relay ladder 1 ogic.

The sequential control chart (SCC) is a graphic oriented programining language for sequencing operations in conjunction with the CCC configuration.

The PCS Relay Ladder Logic allows the programmer to define discrete control functions in the control strategy with logic elements such as coils and relays.

Set point programs are developed with the PC Supervisor to provide input to Set Point Programmer control blocks in the CCC. Each program can contain up to 49 pairs of ramp and soak segments. Each segment can turn on 1 to 12 events through a Set Point Program Event control block in the CCC.

A printed copy of these configuration files will be placed in the computer software description document, WHC-SD-CP-CSWD-018. The configuration file printout wi 11 have the documentation date in the header and will be referenced in the computer software description document.

\subsubsection{Graphical Files}

These files provide graphical representation of the system being controlled or monitored. Graphical files are generated to provide an interface to the CCC configuration. Graphical displays allow real time data monitoring by user. Configuration control will be through reproduction of actual graphics from the DRAW program. An ASCII file report will be generated for each graphic in the DRAW program and will be printed. Each graphic and graphic report wi11 become part of the computer software description document.

\subsubsection{Tag Group Files}

The tag group files are a set of tagnames that can be used in a common graphical display to replace generic tagnames with specific data points. Tag group reports are generated by the Tag Group Editor to an ASCII file that will be printed and will become part of the Computer Software Description Document. 


\subsubsection{Problems, Faults and Failures}

Hardware problems, faults and failures will be reported, controlled. processed, corrected, retested, and closed out using the Job Control System (JCS). Should modifications be required to resolve or correct the problem. the engineering process will be documented according to WHC-IP-0848. PFP Engineering Directives, Section 1.16. "Engineering Design File." The resulting ECN will be developed, processed, approved, and released according to EP 2.2.

Any problems, faults, or failures resultant of the software will have changes done per section 3.2.1 or recovery actions per section 3.2.3.

\subsection{CONFIGURATION CONTROLS}

\subsubsection{Software Changes}

When a change to the software is required. that change will be reviewed by the system administrator and/or cognizant engineer for system being affected. All changes to software files will first be done at the system administrator's development station. An ECN against the computer software configuration document will be written for change. The system cognizant engineer or delegate and cognizant manager must sign al1 ECNs. In addition, the appropriate authorities must sign and approve ECNs based on assigned approval designator. Once ECN is approved for release, the modified software file will be downloaded to the Honeywe 1 MAS replacing the existing file. The Honeywe 11 MAS will be tested to check system configuration as determined by the cognizant engineer. The backup file will be saved on a disk and labeled with "PFP Developed Honeywel1 MAS Control Software." Date of release. and ECN number that changed the software configuration document. The system administrator will maintain the two most recent revisions on disk.

\subsubsection{Access Leve1s}

The Honeywel1 MAS security system is configured by the system administrator. The administrator provides users with a password and provides software abilities based on the user's need.

The system Administrator assigns each user to a user group. Each user group is assigned capabilities required to do their work. Additional capabilities may be provided as needed to the user. 


\subsubsection{Backup and Recovery Operations}

Media control is exercised by the system administrator to ensure that the Honeywell software and PFP developed software is backed up after each modification. This back up will allow reconstruction of the system software in a few days. Two back up copies of the Honeywell and PFP developed software will be maintained. One copy of the software will be maintained on floppy disk by PFP Process Engineering. An additional working copy wi 11 be maintained on the system administrator's computer.

Backup of the PFP developed configuration software can be performed by clicking on "Control Cfg" icon. After logging into the CONFIGURATION ACCESS level, enter the Configuration Library under File menu. Select Configuration Model and press "Backup..." button. Place floppy into selected drive and press "OK" button. The backup file will be saved on a disk and labeled with "PFP Developed Honeywel1 MAS Control Software Configuration, " configuration name, date of release, and ECN or EDT number that released the software configuration document.

Recovery of the PFP developed software wi11 be done by the system administrator. Recovery is accomplished by accessing Configuration Library as describe above and press "Restore..." button. Place floppy with backup files into selected drive. select Configuration to restore and press "OK" button. The nonfunctional configuration file may need to be deleted before restoration. This is done by highlighting the file name and pressing Delete button and then the "OK" button in CONFIRM block. After the configuration is restored, downloading configuration is accomplished by highlighting configuration and pressing "Download..." button.

Graphical and tag group files will be backed up using file manager. Files location is C: Iwdmacs lpic. Graphics designed with the Draw program have (*.odf) tags. Tag groups are saved as (*.tge) files. These files will be saved on a disk and labeled with "PFP Developed Honeywe 11 MAS Control Software - Graphics," disk number (if there are multiple disks), date of release, and ECN or EDT number that released the software configuration document.

Recovery of the Honeywell software will be done by the system administrator per the Honeywell operating manual.

Once any recovery action is complete, the Honeywe 11 MAS wi 11 be tested to check system configuration as determined by the cognizant engineer. 
WHC-SD-CP-CSCM-009, Rev. 0

\subsubsection{Historical Data File}

Historical data files will be collected for designated data points. The data points are specified within Historical Assign and collection is started with Historical Collect. A separate data file is initiated every 24 Hours. The files are retained by the system for 30 days and then are deleted. The data will periodically be exported from Historical Display and loaded into a Microsoft ${ }^{\circledR}$ Excel spreadsheet. The data will be manipulated into graphs and/or tables. These graphs and tables will be maintained by Process Engineering and wi 11 be documented in campaign reports.

\section{3 CONFIGURATION STATUS ACCOUNTING}

The System Administrator will review the software for correctness biannually. The current operating software will be compared with the current revision of WHC-SD-CP-CSWD-018. Honeywe11 Modular Automated System Computer Software Documentation. This review will provide a listing of the following information:

1. Cognizant engineer for controlled system

2. Software custodian

3. Current revision of configuration

4. Location of master and backup configuration and Honeywell files

5. EDT and ECN numbers for documentation.

\subsection{TOOLS, TECHNIQUES, AND METHODOLOGIES}

No additional tool, techniques, or methodologies are used in maintaining configuration control other than those supplied as part of the commercially available Honeywell and FIX MMACS $^{\mathrm{TM}}$ software.

\section{0 SUPPLIER CONTROL}

The cognizant engineer will ensure that the Honeywell MAS software meets the specifications in the purchasing contract.

The cognizant engineer wi11 ensure the Honeywe11 MAS is being supported during all phases of installation, setup, programming and debugging.

\subsection{RECORD COLLECTION AND RETENTION}

See section 3.2.4. 


\subsection{REFERENCES}

MAS-8988C,

Modular Automation System, PC Supervisor Graphics

MAS-8992C.

Modular Automation System. 59000 Controller

MAS-8993C,

Modular Automation System. PC Supervisor

WHC-CM-3-10,

Software Practices

WHC-CM-4-2,

Quality Assurance Manual

QR 19.0, "Software Quality Assurance Requirements"

WHC-CM-6-1. Standard Engineering Practices

EP 1.6. "Engineering Data Transmittal"

EP 1.7. "Engineering Document Approval and Release"

EP 2.2, "Engineering Document Change Control"

EP 4.1. "Design Verification Requirements"

EP 4.2. "Testing Practices"

WHC-SD-CP-CSWD-018. Plutonium Finishing Plant Honeywel7 Modular Automation System Computer Software Document

WHC-SD-CP-ATP-071. Plutonium Finishing Plant Honeywell Modular Automation System Computer Software Acceptance Test. 